\title{
Reflexiones de las ciudades de la Bética recogidas en la Geografía de Estrabón

\author{
M $^{a}$ Luisa Cortijo Cerezo( $\left.{ }^{*}\right)$.
}

\begin{abstract}
RESUMEN.
Se analizan las distintas ciudades citadas por Estrabón en el sur peninsular, especialmente aquéllas que de forma clara reciben apelativos como metropolis, polis, apoikia, ... que les confieren unas características distintivas respecto a las demás. Se intenta saber, aplicando el conocimiento que tenemos de las ideas geográficas de

Estrabón a través de los prolegómenos de su obra, si estos planteamientos básicos han sido aplicados en esta región al tratar el tema del urbanismo y si dicha aplicación ha sido coherente con la declaración de intenciones del autor.

PALABRAS CLAVE:

Estrabón, Geografía, Turdetania, ciudades.

ABSTRACT. Here we analise the various towns mentioned by Strabo in the south of the peninsula, specially those which are clearly named as metropolis, polis, apoikia, ... which confers them some features that make them different from the others. We try to know, applying the knowledge we have of Strabo's geographical ideas through the prologue of his work, if those basic approaches have been applied in this region when dealing with town planning and if this application has been coherent with the author's declaration of intentions.

KEY WORDS: Strabo, Geography, Turdetania, towns.

Muchos son los estudios que se han ocupado de aspectos relacionados con la geografía antigua, en general, y con Estrabón, en particular, en los últimos tiempos ${ }^{1}$. Bien es sabido que este erudito no conoció de primera mano las informaciones relativas a lberia, pero no es menos cierto que sí es el pri-

() Universidad de Córdoba.

- Sólo por citar algunas obras generales y compilaciones, con especial incidencia en Iberia, ver AuJAC, G., Strabon et la science de son temp, París, 1966; Calzoni, A., Conception de la géographie d'aprés Strabon, Lugano, 1940; Cruz Andreotti, G., ed., Estrabón e Iberia: nuevas perspectivas de estudio (en adelante, Estrabón e Iberia), Málaga, 1999; Jones, H. L., The geography of Strabo, Il, Cambridge, 1988, Loeb Classical Library; LASSERRE, F., Strabon. Geographie, tome II, livres III et IV (en adelante, Strabon), París, 1986, Les Belles Lettres; Maddoli, G., ed., Strabone. Contributi allo studio della personalità e dell'opera, II, Perugia, 1986; Meana, M. J./PIÑERO, F., Estrabón. Geografia. Libros III-IV, Madrid, 1992, Bibl. Clásica Gredos; Prontera, F., ed., Strabone. Contributi allo studio della personalità e dell'opera, I, Perugia, 1984; THOLLARD, P., Barbarie et civilization chez Strabon. Ėtude critique des livres III et IV de la Géographie, Paris, 1987; Trotta, F., Strabone. Geografia. Iberia e Gallia, Milán, 1996. Además, son muchos los artículos específicos sobre el tema que han aparecido en los últimos tiempos, algunos de los cuales veremos a lo largo de este trabajo.
\end{abstract}


mero del que conservamos una obra de conjunto sobre la península, con una visión global y un intento de sistematización racional de los datos de que disponía, analizando sus peculiaridades y evitando las explicaciones míticas o poco racionales ${ }^{2}$; pero no es sólo el principal geógrafo de la antigüedad para la península ibérica, sino para todo el mundo conocido, ofreciendo la primera geografía de los países conquistados por Roma durante los S. II-I a. C. Con todo, su obra no fue valorada adecuadamente hasta el S. XIX y, en su época, no fue recordado por Plinio ni por Ptolomeo; técnicamente, podríamos decir que es un autor secundario que, ni por sus contenidos, ni por su estilo, sería una primera figura de su época; su obra no tendría mucha utilidad bajo un punto de vista cartográfico (quizás por ello lo olvide Ptolomeo) y es más una labor recopilatoria que creativa ${ }^{3}$. Pero se ha conservado y otros escritos no, y eso la convierte en algo muy importante para el actual conocimiento de la geografía en dicha época. De todos modos, a pesar de haberle denostado un poco en las lineas anteriores, hemos de reconocer a Estrabón la aportación de una peculiaridad muy loable en la presentación de su trabajo, sintetizada en los inicios del mismo, ya que el prefacio de su obra, como acertadamente expone Prontera, es la más larga, meditada y articulada reflexión de la literatura antigua sobre la naturaleza, el objeto, los fines, los destinatarios y el público de la geografía: nunca se había titubeado tanto al justificar el trabajo emprendido y al buscar explícitamente lectores ${ }^{4}$. Posiblemente podemos ver en esto una declaración de intenciones, y ello nos obliga a juzgar su obra, no como muchas veces se ha hecho ( $\mathrm{y}$ yo misma acabo de hacer), buscando carencias o servidumbres que analizaremos más adelante, sino comprobando si, efectivamente, cumple con las normas que el propio autor se impone; en caso de ser así, nos guste o no el resultado, tendremos que admitir que Estrabón hizo un trabajo excelente.

En dicho prefacio, además, nos deja entrever cuáles son algunas de sus principales fuentes y cuáles aquellas obras o tipos de obras que rechaza como no válidas para su objetivo, lo que nos permite afinar más en cuál fue su intencionalidad al redactar su obra y de qué manera veia la geografia: una geografía práctica, estructurada en continentes, regiones, subrregiones, con una sistematización y racionalización de los espacios a tratar ${ }^{5}$. En su perspectiva del espacio, hallamos uno que no sólo es físico, sino que alcan-

2 Sobre estos aspectos y las fuentes utilizadas por Estrabón, ver, Lasserre, F., Strabon ..., p. 4-15; Meana, M. J./Piñero, F., op. cit., p. 11-15; Ciprés, P., "El impacto de los celtas en la Península lbérica según Estrabón», Estrabón e Iberia, p. 129. Cruz Andreotti, G., “Introducción. Estrabón y la Península Ibérica: una revisión obligada», Estrabón e Iberia, p. 8; Gómez Espelosín, F. J., "Estrabón y la tradición mitica sobre el extremo occidente", Estrabón e Iberia, p. 73-77

3 Meana, M. J./PINERo, F., op. cit., p. 18. Van Paassen, Ch., "L'eredità della geografia greca classica: Tolomeo e Strabone", Geografia e geografi nel mondo antico. Guida storica e critica (en adelante, Geografia e geografi), Roma-Bari, 1990, p. 232 y n. 12.

4 Prontera, F., «Introducción», Geografia e geografi, p. XVIl.

5 Str., II, 5, 13; CIPRES, P., "Celtiberia: la creación geográfica de un espacio provincial», Ktema, 18, 1993, p. 266; PEREZ VILATELA, L., «Itinerario de Polibio en Hispania Ulterior», Actas del VII CEEC, vol. III, Madrid, 1989 , p. 99-125. 
za su razón de ser como soporte de una sociedad, condicionada por ese espacio, pero también con capacidad para transformarlo; la geografía de Estrabón se basa en la sociedad, no en el medio físico. Es una mezcla de geografia, corografía e historia, con unos toques de cosmografía y meteorologia, que intentan convertirla en una ciencia amena y asequible ${ }^{7}$ para un público con un nivel intelectual al menos medio o para personas que deben combinar el aprendizaje y la lectura con otras actividades que ocupan parte de su tiempo (Str., I, 1, 21-23). Es una obra escrita en griego, que usa principalmente fuentes griegas, destinada a una audiencia griega y útil para administradores romanos conocedores de la lengua griega; Estrabón exhibe en ella su orgullo helénico, resaltando la superioridad cultural y artística griega, pero admitiendo tácitamente la capacidad organizativa romana, que es la que les ha hecho dueños de un mundo amplio y pacificado; incluye elementos de disquisición filosófica dentro de un mundo estructurado al estilo romano; lo que refleja la dualidad del público al que se dirigía, donde confluian el filósofo que todo griego culto encierra y el pragmático político romano ${ }^{8}$.

La geografía de Estrabón, él mismo nos lo dice con claridad (Str., I, 1, 8; I, 1,23 ; II, 5, 13) es una geografía al servicio del poder, del militar y del gobernante que, en este caso, es Roma, siguiendo quizás los planteamientos de Polibio ${ }^{9}$. Estrabón es uno de los representantes de las oligarquias locales que, quizás por los avatares sufridos por su patria y su propia familia (Oriente siempre estuvo en manos de los perdedores romanos en los distintos conflictos civiles), estaban habituadas a la presencia romana y, tras un periodo dilatado de inestabilidad y guerras, aprobaban la conquista y el imperialismo romanos, admirando al nuevo poder que se estaba gestando y apoyando el universalismo de la política de Augusto ${ }^{10}$ que, por otra parte, crearon el único ambiente propicio para el surgimiento de una obra de la envergadura de la Geographica de Estrabón que en otro ámbito cultural y político quizás no hubiera sido posible, hecho del que creemos que era consciente el autor. Esto, no obstante, conduce irremediablemente a un cier-

Str., II, 5, 26; ejemplo de Grecia que, a pesar de contar con un medio físico poco apto, la inteligencia y el saber hacer de sus gentes la convirtieron en un modelo de civilización; alusión también a la influencia romana en los territorios conquistados, ARCE, J., "Estrabón sobre la Bética", Estudios sobre Urso. Colonia lulia Genetiva, Sevilla, 1989, p. 215-218; Ciprés, P., "Celtiberia ...", p. 268-271 y n. 42; Dominguez Monedero, A. J., "Reflexiones acerca de la sociedad hispana reflejada en la Geografia de Estrabón», Lucentum, 3, 1984, p. 209-211; Gómez Espelosin, F. J., "Estrabón...”, p. 73-75; Plácido Suárez, D., “Estrabón III: el territorio hispano, la geografía griega y el imperialismo romano", Habis, 18-19, 1987-88, p. $252-255$.

7 Ciprès, P., “Celtiberia...", p. 269-270, Gárcia Blanco, J./Garcia Ramón, J. L., Estrabón. Geografia. Libros I-II, Madrid, 1991, Bibl. Clásica Gredos, p. 109-113; Meana, M. J./Piñero, F., op. cit., p. 18.

8 Alonso Nuñez, J. M., "La Turdetania de Estrabón", Estrabón e Iberia, p. 119 ; Garcia Blanco, J./GarCí RAMón, J. L., op. cit., p. 49; Trotta, F., “Estrabón, el libro lll y la tradición geográfica», Estrabón e Iberia, p. 92-97; Van Paassen, Ch., op. cit., p. 241.

9 Polibio, III, 7, 5-7; IX, 13; IX, 14, 1-4; Ciprés, P., “Celtiberia...”, p. 274; Garcia Blanco, J./Garcia RAMON, J. L., op. cit., p. 113-114 y n. 138.

10 Alonso Núñez, J., “La Turdetania ...", p. 103-104; Cruz Andreotti, G., "Introducción», p. 12-13; Dominguez Monedero, A. J., op. cit., p. 209; Garcia Blanco, J./García Ramón, J. L., op. cit., p. 42-50; Plácido SuAREZ, D., “Estrabón III ...”, p. 244-255. 
to grado de parcialidad, que apreciamos a lo largo de su obra en sus conocidas alusiones al antes y el después de la presencia romana, a los binomios indígena-colono, polis-civilización, aldea-barbarie, que analizaremos para el caso concreto de la Turdetania. Este antes-después coloca como eje cronológico la presencia romana en las distintas regiones, llegando con ella la paz, el desarrollo económico y las costumbres civilizadas ${ }^{11}$.

Este planteamiento general de su geografía, su preferencia por unas $u$ otras fuentes, su desprecio manifiesto por autores como Piteas (ya sea por razones objetivas o personales), su utilización preferente de autores griegos (sólo usa los romanos escasamente y para ciertas actualizaciones puntuales), así como la intencionalidad con la que escribe la obra han sido temas muy debatidos, haciendo pensar a algunos que debemos acercarnos a ella primordialmente como obra literaria, sin grandes pretensiones etnográficas, económicas o sociales ${ }^{12}$, lo que nos ha hecho reflexionar sobre la conveniencia o no de creer sus informaciones de una forma tan leal como se ha hecho hasta hace poco. No vamos ahora a negar la riqueza de datos que nos ha aportado ni la veracidad de muchos de ellos, pero la intencionalidad con que se escribe una obra determina, en parte, los resultados de la misma $y$, aunque no se incorporen falsedades de gran entidad, bien es cierto que se puede adulterar la realidad, no ya por lo que se dice, sino por cómo se interpreta lo dicho o por lo que directamente se omite. Bajo este presupuesto, aceptando la creencia generalizada de que Estrabón es un autor que entiende su geografía como un instrumento útil al poder, pero sin radicalizar una postura de servilismo hacia el estado romano, queremos releer algunas de sus informaciones sobre las ciudades turdetanas.

Nos interesan especialmente dos párrafos de su Iberia, en los que se recoge de una forma bastante sincrética su visión sobre las ciudades, tanto hispanas como béticas, incluyendo en pocas líneas una amplia terminología que está siendo objeto de estudio por nosotros en otro trabajo. El primero de ellos, relativo a lberia en general, aunque incidiendo en el mundo celtibérico, es el siguiente: «Pero cuando Polibio dice que Tiberio Graco destruyó trescientas de sus ciudades (poleis), Posidonio, burlándose, responde que con

11 ARCE, p. 218-219; esta idea es una constante en Clavel-Lévêque, M., "Les Gaules et les Gaulois: pour une analyse du funcionnement de la Géographie de Strabon", D.H.A., 1, 1974, p. 75-93; Plácido Suárez, D., "Estrabón III ...", p. 255-256, con muchas citas relativas a Hispania; Sayas Abengochea, J. J., «Unidad en la diversidad. La visión de Estrabón de algunos pueblos peninsulares", Estrabón e Iberia, p. 153. Aunque somos concientes de que el término Turdetania puede ser utilizado siguiendo diversos criterios, en este caso, entendemos por Turdetania la región que constituiría la provincia romana de la Bética; lo hacemos con criterio operativo, únicamente para evitar expresiones-rodeo como "sur peninsular", "sector meridional de la provincia Hispania Ulterior "..., y con voluntad consciente de no denominarla Bética ya que. aunque Estrabón recoge la noticia de la división provincial tripartita de Hispania, lo hace, en nuestra opinión, como un añadido posterior a una obra ya redactada con anterioridad a este hecho y no alterada significativamente por él. También hemos intentado que la grafía de las ciudades sea "lo más griega posible", adoptando la de Meana, M. J./Piñero, F., op. cit.

12 ARCE, J., op. cit., p. 213; no obstante, Prontera, F., "Introducción", p. XII, lo ve como un término medio entre el género literario y el saber cientifico, y quizás esto sea to más correcto. 
esto el hombre trata de halagar a Graco, denominando ciudades a los baluartes (pyrgous), como se hace en los desfiles triunfales. $Y$ no deja quizás de ser cierto lo que dice, pues tanto los generales como los historiadores se dejan arrastrar fácilmente a este tipo de embuste por embellecer los hechos. Es el caso también de los que sostienen que pasan de mil las ciudades (poleis) de los iberos, los cuales me parece que llegan a este número otorgando el nombre de ciudades (poleis) a las aldeas grandes (megalas komas). Porque ni la naturaleza del país (joras) puede admitir muchas ciudades (poleon) por su escasez de recursos ni por su aislamiento y primitivismo, ni su modo de vida ni sus acciones, salvo los de la costa del Mar Nuestro, sugieren nada de esto: son salvajes los que viven en aldeas (komas), y como ellos la mayoria de los pueblos iberos; y tampoco dulcifican fácilmente las costumbres las ciudades (poleis) cuando son multitud los que viven en los bosques para daño de sus vecinos" (Str., III, 4, 13) ${ }^{13}$. El párrafo sintetiza parte de la ideología estraboniana sobre lo que ha de ser la geografía y sobre los lugares que requieren el interés del geógrafo, y podemos afirmarlo así porque el propio autor, en su prefacio a la obra, lo afirma explicitamente. En primer lugar, el objeto de estudio de Estrabón no es la geografía física, como ya hemos comentado, sino el espacio en tanto que es habitado y modificado por el hombre y, dentro de este espacio, es de especial interés, como hemos dicho, el que mantiene relaciones amistosas con Roma; sabe que existen otras tierras, pero no las considera dignas de estudio: "Lo que nosotros deseamos conocer son precisamente aquellas regiones en las que existe una mayor tradición de hazañas, de regímenes poiíticos, de técnicas y de todo lo demás que contribuye a la sabiduría, así como nuestras necesidades nos conducen hacia aquellos países accesibles al intercambio y las relaciones, $y$ ésos son los que están habitados y sobre todo los que están bien habitados» ${ }^{14}$; Europa, de forma particular, «es la más favorable para la superioridad de hombres y regímenes políticos y a la que más se ha distinguido por su transmisión a otros continentes de sus bienes propios, puesto que toda ella es habitable excepto una pequeña parte inhabitable por el frío ... aunque con un buen gobierno incluso las zonas pobres y llenas de bandidos se civilizan» (Str., II, 5, 26); “Las regiones situadas más al Norte y que ya están cerca de la zona deshabitada a causa del frío, carecen de utilidad para el geógrafo" (Str., II, 5, 43).

A pesar de la modernidad que muchas veces apreciamos en la concepción estraboniana de la geografía, este sentido práctico y utilitario de su ciencia excede la practicidad con que hoy día se aborda esta materia: sólo es útil la geografía que está al servicio del hombre y, añadimos nosotros, ya que su

\footnotetext{
${ }_{13}$ Las traducciones están tomadas de Meana, M. J./PIÑERo, F., op. cit, conservando las palabras griegas que nos interesan tal y como se transcriben del texto, admitiendo asi la posibilidad de que textos griegos distintos ofrezcan lecturas diversas. Texto griego consultado conjuntamente en Lasserre, F., Strabon... y Jones, H. L., op. cit..

${ }_{14}^{14}$ Str., II, 5, 18. Para los libros I-II de Estrabón, hemos seguido la traducción de Garcia BLANCO, J./GARCia RAMÓN, J. L., op. cit.
} 
obra está dirigida a eruditos y gentes de mando, sólo es útil la geografía que satisface las mentes de los hombres cultos y las necesidades de los gobernantes, en este caso, los representantes del Estado romano (lo que nos conduce a un Estrabón profundamente griego, pero plegado a la época en que le tocó vivir). Con todo, como hemos dicho, la Iberia de Estrabón no pretende ser una obra actualizada ${ }^{15}$, sino un compendio de aquellas cosas útiles a los hombres de su tiempo, lo que pensamos que suaviza un poco la creencia de que es un fiel servidor del poder, ya que la lberia que nos presenta puede recoger una verdad a nivel general, pero no plasmar cada una de las realidades concretas de la península; por eso Estrabón, a pesar de defender a ultranza la figura de Homero en algunos largos párrafos de su relato sobre Iberia ${ }^{16}$, nos muestra una Turdetania que ha perdido su posición marginal de extremo occidente (a lo que contribuiría el uso de Polibio, Posidonio y Artemidoro como fuentes) en parte gracias a la intervención romana; Estrabón quizás sea el primer testigo de la ruina definitiva del mito occidental, como consecuencia de la presencia romana en el territorio y del mejor conocimiento de éste ${ }^{17}$. El segundo concepto importante que se desprende de este párrafo es la idea de que la civilización va indisolublemente ligada al desarrollo de las ciudades, mientras la barbarie es propia de los asentamientos aldeanos (III, 2,15 ; III, 3, 5; III, 3, 8; III, 4, 13, como citas representativas). Para él, sólo la vida urbana es propia de las gentes civilizadas, mientras que las aldeas y los bosques son el hábitat natural de las gentes bárbaras (algunas explicaciones del bandolerismo hispano tienen que ver con esta vida salvaje y la difícil accesibilidad de las gentes a regiones distintas a las suyas), concretando más aún, y en lo relativo a todos los pueblos (salvo quizás los griegos y algunos orientales), la mayor civilización se da en aquellas zonas más accesibles a la presencia romana, más próximas a Roma o que mejor se han adaptado a la presencia romana ${ }^{18}$. Con todo, se destaca que la mayor parte de lberia es pobre, poco habitada, con relieve accidentado, con poblaciones dispersas y aisladas y, por tanto, con pobladores salvajes cuyo hábitat indiscutido son las

15 Utiliza autores básicamente griegos y anteriores a él, y poco a romanos como Asinio Polión; LASSERRE, F., Strabon ..., p. 8-10.

16 Str., III, 2, 12-14; III, 4, 4; no olvidemos que fue considerada durante mucho tiempo una tierra extrema, sede de mitos y leyendas. En general, CIPRÉS, P./CRUz ANDREotTI, G., «El diseño de un espacio político: el ejemplo de la Península lbérica", Los límites de la tierra: el espacio geográfico en las culturas mediterráneas, Madrid, 1998, p. 109; Cruz ANDREOTTI, G., «Estrabón y el pasado turdetano: la recuperación del mito tartésico", Geographia Antiqua, 2, 1993, p. 13-31; Idem., "La visión de Gádira en Estrabón: elaboración de un paradigma geográfico», DHA, 20.1, 1994, p. 57-85; Idem, "La Península lbérica en los límites de la tierra: el caso de Tartesos», Polis, 7, 1995, p. 39-75; Gomez Espelosin, F. J., “Estrabón ...», p. 63-79; Trotta, F., «Estrabón ...», p. 96-97

17 Alonso Nuñez, J., "Les informations de Poseidonius sur la Péninsule Ibérique», A.C., 48, 2, 1979, p. 639-646; Idem, “Les renseignements sur la Péninsule lbérique d’Artemidore d'Éphèse”, A.C., 49, 1-2, 1980, p. 255-259; Idem, “Das Bild der Iberischen bel Polybios», A.C., 54, 1985, p. 259-266; GoMEZ ESPELOsin, F. J., “Estrabón ...», p. 77.

18 Alonso NúN̄EZ, J., "La Turdetania ...", p. 101-12 y 112-115; Arce, J., op. cit., p. 215; Garcia BlanCo, J./Garcia Ramón, J. L., op. cit., p. 154-155; Gomez Espelosin, F. J., “Estrabón ...”, p. 73-75; Gómez Espelosin; F. J./Perez Lacharga, A.Nallejo Giaves, M., La imagen de España en la Antigüedad Clásica, Madrid, 1995, p. 129 y n. 73. Con todo, en lo relativo a la cuestión de las formas de hábitat, tal vez habria que tener 
aldeas y las zonas agrestes. Sólo para la costa del Mar Nuestro plantea una situación que encajaría con parámetros civilizados al estilo greco-romano, aunque esta generalización, centrada en Nuestro Mar, habría que ampliarla integrando, al menos, toda la Turdetania, cuya descripción detallada abunda en alusiones de este tipo. Así, junto a las mil discutibles ciudades de Iberia o las trescientas también discutibles de Celtiberia, Estrabón habla de doscientas ciudades para la Turdetania (que Plinio disminuye a 175 en la Bética), una región civilizada, que mira al mar, que tiene prósperas ciudades ubicadas en costa, ríos, esteros y lugares de fácil acceso y que, acostumbrada ya a la civilización urbana (aportada en buena medida por antiguos colonizadores que llegaron procedentes del ámbito mediterráneo), acepta con cotidianeidad el modo de vida romano que es, en sí mismo, el modelo de la civilización de su tiempo.

Para esta Turdetania civilizada, como hemos dicho, Estrabón acepta sin problemas la existencia de doscientas ciudades: "La extensión de este país (Turdetania) no es, en longitud y anchura, superior a dos mil estadios, pero sus ciudades son extraordinariamente numerosas, pues se dice que llegan a doscientas. Las más conocidas son las que se alzan a orillas de los ríos, los esteros y el mar, debido a su ventajosa situación ..." (Str., III, 2,1). Se considera que el número de doscientas para este territorio es muy elevado, algo digno de ser destacado como hecho muy por encima de lo normal. La idea conecta con la recogida en el párrafo anteriormente citado, al ser la Turdetania un sector integrante, a niveles generales, en esa costa que vierte al Mar Nuestro; sobre la región atlántica, que cubre también un amplio sector de la Turdetania, la consideración que a lo largo de toda la obra se hace de Gádira, y que veremos más adelante, nos permite integrar en este panorama romanizado y romanizador todo el área de influencia de esta activa y filorromana ciudad, que llegó a alcanzar un censo de 500 caballeros, a pesar de ocupar una posición extrema en la ecumene. No creemos necesario incidir en este carácter eminentemente urbano del sur peninsular, hecho reflejado muy frecuentemente en las fuentes literarias y confirmado y ampliado por la epigrafía, así como por los testimonios arqueológicos; menos aún pretendemos presentar un elenco de dichas ciudades, ya que ello escaparia a las limitaciones y objetivo de este estudio; por lo pronto, sólo nos interesan las ciudades explícitamente citadas por Estrabón y, dentro de ellas, aquéllas que van claramente acompañadas del apelativo «polis».

Otro punto a destacar de este párrafo es que Estrabón nos dice que las más conocidas son las que se hallan en las orillas de los ríos, los esteros

en cuenta que Estrabón utilizó básicamente fuentes griegas y romanas, o sea, personas acostumbradas a vivir en o a ver ciudades, por lo que nos parece muy acertada la idea de LoPez PAz, P./PEREIRA MENAUt, G., "La tierra y los hombres: paisaje politico, paisaje histórico", Studia Historica. Historia Antigua, 13-14, 19951996, p. 44: “Un observador acostumbrado a ver ciudades y quizás también a vivir en ellas podrá notar, en otro caso, que no hay ciudades, sino solamente pequeñas aldeas, según lo que él entienda por tales". 
y el mar. Tendriamos que analizar si ése «las más conocidas" se plantea bajo un punto de vista subjetivo u objetivo; o sea, iéstas son las ciudades más conocidas de Turdetania en general, las más conocidas por todos los habitantes de lberia o, por el contrario, son las más conocidas para las gentes de fuera, para los griegos y romanos, eruditos $u$ hombres de armas o gobierno, que miran hacia Turdetania con los ojos puestos en sus propios intereses? Es cierto que Estrabón es un greco-romano que escribe para griegos y romanos, y cuya geografía tiene una finalidad claramente práctica para los hombres de gobierno romanos, por tanto, las ciudades más conocidas de Estrabón han de coincidir, casi seguramente, con las más convenientes de conocer para los intereses del conquistador. Lo que interesa a Estrabón y al público griego y romano de su obra son aquellos lugares que les sean de utilidad, $y$ «... nuestras necesidades nos conducen hacia aquellos países accesibles al intercambio y las relaciones, y ésos son los que están habitados y sobre todo los que están bien habitados" (Str., II, 5, 18); qué duda cabe de que Turdetania es una zona que encaja en esta descripción, dada la riqueza que se supone que encierra y la relación fructífera, desde tiempos remotos, con pueblos civilizados y urbanos. De hecho, la geografia arcaica griega se fundamenta en buena medida en este sentido de intercambio y utilidad, ya que se desarrolla al amparo y al servicio de la colonización ${ }^{19}$. Así, a Estrabón, del sector béti$\mathrm{co}$, le atrae el alto nivel de producción tanto agraria como minera (se comenta más detalladamente que para los demás sectores de Iberia); la accesibilidad de sus ciudades, bien comunicadas por su ubicación en esteros, ríos, costa (Str., III, 2, 4-5) o cerca de vías terrestres (Estrabón destaca en Iberia la que la conecta directamente con Roma; Str, III, 4, 9); la navegación, los peligros del mar y la casi exclusividad de las intensas relaciones comerciales con Roma e Italia (Str., III, 2, 5-6); Gádira, pese a su ubicación en el extremo occidente, es famosa precisamente por su capacidad comercial y por las excelentes relaciones que mantiene con los romanos (Str., III, 1, 8; III, 2, 1; III, 4, 3; III, 5, 3; básicamente) ${ }^{20}$.

Un análisis más detallado de las ciudades citadas por Estrabón nos aclarará, al menos en parte, hasta qué punto se citan sólo aquéllas que encajan en este perfil previo de civilización-romanización-utilidad, que en nuestro autor es un presupuesto general válido para toda la ecumene. De las doscientas ciudades que reconoce en Turdetania cita sólo treinta y cuatro: Ábdera (III, 4, 3; III, 4, 6) ${ }^{21}$; ¿Aigoua?-Aspavia (III, 2, 2) ${ }^{22}$; Asta (III, 1, 9; III, 2, 2; III, 2, 5); Astigis (III, 2, 2); Ategua: III, 2, 2); Belón (III, 1, 8); Be-

${ }_{19}$ A nivel general, Ciprés, P./Cruz Andreotti, G., op. cit., p.125-133; Garcia Blanco, J./Garcia Ramón, J. L., op. cit., p. 42-61.

${ }^{20}$ Plácido Suárez, D., “Estrabón ...», p. 247-254.

21 Meana, M. J., Estrabón ..., p. 94 no la cita en el segundo caso; el texto griego sí.

22 García y Bellido, A., España y los españoles hace dos mil años, según la Geografia de Strabón, Madrid, 1968 , p. $70-71$ y n. 77 habla de Aigua y Meana, J. M., op. cit., p. 50 y n. 54, traduce Aspavia; el texto griego dice Aigoua, y Jones, H. L., op. cit., p. 21, n. 2, dice que es una ciudad desconocida, pero cree que Escua es probablemente la lectura correcta. 
tis (III, 2, 1), ¿Calpe? (III, 4, 2; III, 5, 3; III, 5, 5); Carteya (¿III, 1, 7?; III, 2, 2; III, 2, 7); Carmon (III, 2, 2); Corduba (III, 2, 1; III, 2, 2; III, 2, 3; III, 4, 9); Cotinas (III, 2, 3); Ebura (III, 1, 9); Gádira (I, 2, 31;II, 3, 4; II, 3, 5; II, 4, 1; II, 4, 2; II, 4, 4; II, 4, 8; II, 5, 14; II, 5, 15; II, 5, 30; III, 1, 5; III, 1, 8; III, 1, 9; III, 2, 1; III, 2, 11;III, 2, 13, III, 4, 2; III, 4, 3; III, 4, 9; III, 5, 3; III, 5, 4; III, 5, 5; III, 5,6 ; III, 5, 7; III, 5, 8; III, 5, 9; III, 5, 10; IV, 4, 6; XVII, 3, 2; XVII, 3, 4); Hispalis: (III, 2, 1; III, 2, 3), Ilipa (III, 2, 2; III, 2, 3; III, 5, 9); Italica (III, 2, 2); lulia loza (III, 1, 8); Malaca (III, 4, 2; III, 4, 6; III, 4, 10; III, 4, 14); Menace (III, 4, 2); Mainoba (III, 2, 5); Menlaría (III, 1, 8); Munda (III, 2, 2; III, 4, 9); Nabrissa (III, 1, 9; III, 2, 5); Obulcon (III, 2, 2; III, 4, 9); Odisea (III, 2, 13; III, 4, 3); Onoba (III, 2, 5; III, 5, 5); Osonoba (III, 2, 5); Sisapon (III, 2, 3); Sexi (III, 4, 2; III, 5, 5); Tartesos ( (III, 2, 11; III, 2, 12 III, 2, 14), Tuccis (III, 2, 2); Ulia (III, 2, 2); Urson (III, 2, 2); entre ellas hemos de considerar alguna dudosa: Aigoua, Betis (que sí es citada como ciudad vecina al río Betis, pero que no sabemos la entidad que tuvo en sí misma, ya que no aparece en otras fuentes y la referencia que a ella se hace es más ideológica que de otra índole), Calpe (que puede asociarse a Carteya, ya que la alusión a Calpe en prácticamente todas las ocasiones nos habla del referente geográfico observable desde el mar, famoso por los planteamientos míticos y la periplografía) ${ }^{23}$, Cotinas ${ }^{24}$; Ebura (considerada por Mela, III, 4, como un castellum, con lo que no tendría la entidad de polis), Menlaría ${ }^{25}$, Odisea (de la que no podemos concretar si existió realmente o no) y Tartesos (ciudad que es evidente que no hemos de incluir en las estadísticas de Estrabón, al tratarse de un lugar desaparecido hace mucho tiempo, estando así

23 En Str., III, 1, 7, Meana, M. J., op. cit., siguiendo el texto griego, cita Calpe, pero la nota adjunta nos aclara que se está refiriendo a la fundación colonial de Carteya, p. 44 y n. 32 . El texto griego dice Kalpe polis. JoNES, H. L., op. cit., p. 14, n. 1 dice que autores anteriores han corregido, innecesariamente, Calpe por Carteya y que los autores antiguos, al describir la vía costera desde Malaca a Gádira, recordaron a Całpe y su próxima vecina Carteya como una única parada. En el It. Antonino, la parada es llamada Calpe Carteyam (406, 3; sin embargo, sólo aparece Carteya en el Anónimo de Rávena, 305, 11 y 344, 5 y en la Guidonis Geographica, 516, 4; referencias tomadas de Roldán Hervás, J. M., Itineraria Hispana. Fuentes antiguas para el estudio de las vías romanas en la Peninsula Ibérica, Valladolid-Granada, 1973). En las referencias, se explicita que la Kalpe estraboniana es un monte sólo en dos casos. III, 1, 7 y III, 4, 1; en un tercero puede estar claramente insinuado al hablar de los promontorios que forman las columnas, III, 5, 5; en los demás, aparece como punto referencial visual costero: II, 4, 8, III, 21, III, 2, 11, III, 4, 2 o como punto de partida de distancias: III, 1, 8 y III, 5, 3. Así, las alusiones a Kalpe se mueven prácticamente siempre en un ámbito referencial maritimo propio de los periplos, que eran, como hemos visto con anterioridad, una fuente importante para los geógrafos griegos. La Kalpe polis quizás si habria que identificarla, pues, con Carteya, que aparece implicitamente como ciudad en Str., III, 2, 2 y III, 2, 7. Ver Tovar, A., Iberische Landeskunde, band I. Baetica, Baden-Baden, 1974, p. 70-73.

24 De ubicación desconocida. Para todas las localizaciones, nos hemos servido, a nivel general, de Tovar, A., op. cit.; Garcia y Bellido, A., España y los españoles hace dos mil años, según la Geografía de Estrabón, Madrid, 1968; RoldÁN HeRvás, J. M., op. cit., los volúmenes actualizados y publicados del CIL II y las diversas traducciones comentadas ya citadas del libro III de Estrabón. Por lo que sóto citaremos a par* tir de ahora algunos estudios específicos, dando ya por sentada la referencia a estas obras.

${ }_{25}$ Sobre su ubicación, ver Tovar, A., op. cit., p. 68; Meana, M. J./Piñero, F., op. cit.. Es la misma Menlaría costera de Mela y Plinio; aparece como vicus en Plin. III, 3, 3, por lo que habriamos de descartar su inclusión entre las ciudades, ya que el propio Estrabón se limita a citarla, sin otorgarle una condición urbana concreta. 
en la misma situación que Odisea o Menace ${ }^{26}$. Descartadas estas ocho, nos quedan veintiseis ciudades citadas por Estrabón, pero no a todas ellas les coloca un apelativo delante que nos indique si son polis, megale kome, kome, ... Pasemos a analizar las que sí reciben un apelativo concreto. No vamos a hablar de las que se lo supongamos, porque de lo que se trata es de analizar la información transmitida por Estrabón, no de modificarla.

Aparecen junto al apelativo polis: ¿Calpe-Carteya? (III, 1,7), Belón e lulia loza (III, 1, 8), Ebura (III, 1, 9, que ya hemos dicho que es castellum en Mela), Gádira (III, 2, 1; III, 5, 3; III, 5, 4; III, 5,5; III, 5, 7), Ilipa (III, 2, 3), Tartesos (III, 2, 11); Odisea (III, 2, 13), Malaca y Menace (III, 4, 2), Sexi (III, 4,$2 ;$ III, 5, 5) y Onoba (III, 5, 5). Un total de 12 centros urbanos, de los que habríamos de descartar a Tartesos (que sería en estos momentos un recuerdo mítico), Odisea (prácticamente por los mismos motivos, aunque su existencia sería aún más hipotética que la de Tartesos), Menace (de la que se dice con rotundidad que en esos momentos estaba destruida) y Ebura (es la única contradicción patente, ya que Menlaría, el otro caso de una no polis, no aparece con el apelativo en Estrabón, sino simplemente citada). Las tres primeras ciudades se encuadran en un contexto claramente griego y casi mítico, y, al menos, todas encierran algo oscuro en su origen o su historia que no nos permite hacer grandes precisiones sobre el tema:

- Menace, confundida por algunas fuentes con Malaca, parece ser una coIonia focea, aunque los hallazgos arqueológicos en la zona no apoyan excesivamente esta idea. Su nombre podría relacionarse con la fabricación de garum, hecho que cuadra perfectamente en el entorno de la ciudad. Estrabón la identifica como griega, diferenciándola de Malaca ${ }^{27}$.

- Odisea: los autores que no descartan de entrada la invención de esta ciudad, la han relacionado, por la similitud del nombre, con Oducia o con Ulisi, siendo quizás más adecuada la segunda adscripción, aunque sea por el solo hecho de que la ubicación geográfica de Ulisi se encuadra más en el ámbito costero o semicostero que enmarca la descripción estraboniana en ese momento: "al interior de estos lugares (léase Malaca-Sexi-Ábdera), en la zona montañosa» (Str., III, 4, 3) ${ }^{28}$.

26 Frente a toda la bibliografia que podriamos citar sobre Tartesos, deseamos sólo destacar el pequeño articulo de Alvar, J., "Tartesos-ciudad=Cádiz. Apuntes para una posible identificación», Gerión. Anejos II, 1989. Estudios sobre la Antigüedad en homenaje al Profesor Santiago Montero Diaz, p. 295-305, por el planteamiento que realiza sobre la, según él, no existencia de una ciudad indigena llamada Tartesos y por sistetizar brevemente el estado de la cuestión.

27 Para todo lo relativo a Menace, ver Castillo, J. A. del, «Menace ¿una colonia focea inexistente?, Rivista di Studi Fenici, XVII, 1, 1989, p. 103-116; Jacob. P., "Notes sur la toponymie grecque de la côte méditerranéene de l'Espagne antique", Ktema, 10, 1985, p. 264-265.

28 TOVAR, A., op. cit., 135-136; Salinas de Frias, M., "Sobre las fundaciones de héroes griegos en tberia en el libro IIl de la Geografia de Estrabón", Homenaje al profesor Presedo, Sevilla, 1994, p. 203-215, hace notar la posible filiación ateniense de tales relatos, que pudieron difundirse hacia el S. II a. C. y que Estrabón conocería y recogería, pero, aunque afirma que la Odisea del sur peninsular es prácticamente la única de estas ciudades griegas miticas de la península que podría encuadrarse en un ámbito colonial griego, no entra en la consideración de si el nombre puede esconder la helenización de una población ibera realmente existente;tampoco es ése el objetivo de su estudio. 
- Tartesos: no deseamos entrar en consideraciones sobre la ciudad, porque requeriría un manual sólo para ella y cualquier cita excedería los límites de este trabajo, pero no existía ya en época de Estrabón y eso es lo que realmente importa a nuestro propósito.

Las tres, con todo, a pesar de las difíciles ubicaciones de Tartesos y Odisea, se hallarian en un contexto pseudocostero (en o próximo a la costa) y serían, pensamos, objeto de atención de los periplos, a través de los cuales pudo pasar buena parte de la información a Estrabón. La estructura seguida en la descripción del sur peninsular es clara, con una primera descripción de la costa atlántica y las tierras del interior occidental y, después, descripción de la costa mediterránea y de los territorios del interior, siguiendo los métodos propios de los periplos, aunque él, en sus consideraciones, critique en buena medida a las obras tipo portulanos, periplos y períodi gês ${ }^{29}$. Estrabón utiliza como una de sus fuentes directas a Artemidoro, que escribió un periplo hacia el 100 a. C. comenzando en el Promontorio Sacro y desplazándose hacia el este; Artemidoro pretendió escribir una obra que intentaba ser un mapa de ciudades y distancias, intentando calificar a las ciudades de la forma más correcta, teniendo en cuenta su condición de ciudad, aldea, puerto, fondeadero, ... lástima que, a diferencia de lo que ocurre con los libros V y VI de Estrabón, las referencias a Artemidoro en su libro III parecen ser todas de segunda mano, transmitidas a través de Posidonio y, a pesar de que Estrabón utiliza diferente terminología para designar a las ciudades, no to hace, como hemos visto, con excesivo rigor y método ${ }^{30}$.

Descartados estos tres centros (Menace, Odisea y Tartesos), nos quedan nueve (creemos que es mejor dejar a Ebura en el grupo de las polis ya que, independientemente de la categoría que le otorga Mela, lo que de ella sabemos se integra más en este grupo que en otros; en otro momento, haremos un análisis comparativo de la terminología usada por diversos autores a la hora de definir a un mismo centro y ése será el lugar para abordar este tema), fácilmente identificables, que reciben explícitamente el apelativo de polis y sólo en dos ocasiones más de una vez: Sexi, en dos momentos y Gádira, en cinco. De la segunda ciudad cabría esperarse esto por la entidad que se le da en otros muchos párrafos y por su carácter de referente geográfico, mítico y cultural, pero, ¿qué tiene Sexi que no tengan otras de las ciudades citadas? Lo único que se dice de ella es que está en la costa y que con su nombre se designa a sus salazones (III, 4,2$)$ y también que fue el primer lugar elegido en la fallida fundación de Gádira (III, 5, 5); en ambos casos

29 Str., Vili, 1,1; Garcia Blanco, J./Garcia Ramón, J. L., op. cit., p. 5-61; Meana M. J./Piñero, F, op. cit., p. 11-15; Gómez ESPELOSin, F. J., El descubrimiento del mundo. Geografia y viajeros en la antigua Grecia, Madrid, 2000, p. 244-247; Prontera, F., “Introducción", especialmente, p. XVIII, n. 15.

30 Gómez Espelosin, F. J., El descubrimiento..., p. 240-245; Lasserre, F., Strabon ..., p. 7, n. 1, aunque algunos sostienen que Estrabón utilizó a Artemidoro de primera mano, como recoge Lasserre, F., Strabon ..., p. 12, n. 1; Pédech, P. “La géographie urbaine chez Strabon», Ancient Society, 2, 1971, p. 239-240 
se la cita por el gentilicio de sus habitantes (ciudad de los Sexitanos) y no con su nombre propio. La información tampoco podríamos decir que es muy amplia y la segunda referencia la relacionamos más con Gádira que con la propia Sexi, que sólo se cita al servicio del relato de la fundación de la primera ciudad, que sí es la que realmente se despega de todas las demás en el número de referencias, la variedad y la entidad de las mismas. Así, creemos que Sexi, en realidad, es citada por sí misma sólo en la primera alusión, al igual que otras muchas ciudades cercanas. Todos estos centros ${ }^{31}: ¿ \mathrm{Cal}-$ pe-Carteya? (Carteya, San Roque, Cádiz; Calpe, Peñón de Gibraltar), Belón (despoblado de Bolonia, unos $15 \mathrm{kms}$ al oeste de Tarifa), lulia loza (Tarifa), Ebura (Cjo de Ébora, $6 \mathrm{kms}$ al este de Sanlúcar de Barrameda), Gádira (Cádiz), llipa (Alcalá del Río), Malaca (Málaga), Sexi (Almuñécar) y Onoba (Huelva), presentan varias peculiaridades:

- Todos, salvo llipa, se hallan en un contexto costero o insular; llipa es citada en el curso del Betis como lugar al que se puede llegar con navíos pequeños (III, 2, 2), en cuya región abunda la plata (III, 2, 3) y ubicada a unos setecientos estadios del mar, sintiéndose en ella el influjo de las mareas (III, 5, 9). Los demás lugares jalonan las costas, tanto atlántica como mediterránea, de la Turdetania. Podríamos imaginar que los lugares que Estrabón especifica que son ciudades, parecen proceder de fuentes periplológicas griegas o de la influencia de Artemidoro, en el que abundarían las referencias a ciudades y, sobre todo, a las costas y sus distancias. Para el caso concreto de llipa, podemos reconocer la influencia de Posidonio, que estuvo un mes en Gádira y aprovechó para remontar el Betis hasta llipa (III, 5, 9), mientras Artemidoro no vio el interior de la región ${ }^{32}$.

- Buena parte de ellos se encuadran en un contexto colonial púnico o romano, o de asentamiento de colonos; es el caso de Carteya, Belón, lulia loza, Gádira, Malaca y Sexi. Las demás ciudades, Ebura, Ilipa y Onoba son citadas más en referencia a su interés como centros económicos o bien comunicados, hechos también muy importantes en la descripción general de la Turdetania de Estrabón.

Cierto que otras ciudades lo serían, aunque no se les califique explícitamente de tales, ya que hay alusiones genéricas a la riqueza urbana de Turdetania y otras, también genéricas, al urbanismo de alguna zona en concreto dentro de la misma (como esteros, orillas del Betis, costa del Mar Nuestro, ...). También es cierto que aparecen otros apelativos que nos indican la auténtica entidad de un centro, como metrópolis (aplicado a Munda,

${ }^{31}$ No pretendemos hablar en detalle de ellos por ser sobradamente conocidos y por no engrosar este trabajo con información y páginas que nos parece que no son necesarios. Nos interesa especialmente de ellas su ubicación y alguna caracteristica concreta; para lo primero, ver nota 24; para lo segundo, como hemos dicho, incorporaremos donde corresponda algún trabajo específico.

32 Alonso NúNeZ, J., "Les renseignements ...", p. 255-259; LASSERRE, F., Strabon .., p. 7 n. 1 y p. 13-14. 
III, 2, 2 y Tarracon, III, 4, 7), dipolis (Emporio, III, 4, 8), apoikia (Corduba e Hispalis en III, 2, 1 y Gádira, en III, 5, 5) ${ }^{33}$.

Con todo, esto sólo nos permite integrar en la lista tres centros más: Munda, Corduba e Híspalis, los tres muy conocidos y con un alto status, discutible sólo para el caso de Munda; Corduba e Hispalis entran plenamente dentro del grupo de ciudades que han recibido el status colonial o importantes aportes de colonos romanos. Munda aparece más, creemos, por motivos ideológicos, vinculados a la trascendencia que la campaña de Munda tuvo en la evolución posterior de la historia política de Roma. Sintetizando, tenemos fundaciones fenicias (Gádira, Malaca, Sexi), fundaciones romanas o con aportación de colonos romanos constatada en mayor o menor grado ( $¿ \mathrm{Cal}-$ pe-Carteya?, lulia loza, Corduba, Hispalis), participación especial en el enfrentamiento entre César y los hijos de Pompeyo (Munda, citada en dos ocasiones, pero en el mismo contexto), motivos relacionados con las comunicaciones e, indirectamente, con el comercio (llipa, citada en tres ocasiones: sobre el Betis, navegable con pequeños barcos y lugar donde llega el influjo de la marea; Onoba, sobre los esteros, aunque también se la cita como destino del segundo viaje realizado para fundar Gádira; Belón, que seria promocionada después pero que Estrabón la considera puerto, emporion y lugar con riqueza de salazones; Ebura, en la línea de la costa). Vemos, pues, que las ciudades que implícitamente llevan un apelativo urbano, se vinculan con la labor colonizadora de los fenicios o los romanos, o bien con actividades económico-comerciales muy ligadas a una buena situación geográfica, en lugares fácilmente accesibles, o sea, se adaptan perfectamente a los requisitos previos que Estrabón establece para que un lugar o ciudad sea digno de ser mencionado y útil a las personas a las que va dirigida su obra.

La alusión a Munda está más vinculada, en mi opinión, a motivos ideológicos o propagandísticos ${ }^{34}$, pero se dice de ella que, en cierto modo, fue (en pasado) la metropolis de su territorio, lo que implica una cierta entidad política y también económica, ya que Estrabón otorga este apelativo a capitales de pueblo o país ${ }^{35}$. Estrabón sería consciente de la importancia de la victoria de César, no sólo para sí mismo, sino para explicar la posición que Augusto detentaba en la Roma del momento. Nos quedamos en total con ¿CalpeCarteya?, Belón, lulia Ioza, Ebura, Gádira, llipa, Malaca, Sexi, Onoba, Munda, Corduba e Hispalis, de entre las doscientas ciudades citadas por Estrabón. Aunque habla mucho y de forma muy loable del grado de urbanismo de nuestro territorio, no es ese punto el que más le interesa a la hora de desarrollar su obra. Plinio, bastante más escueto en otros aspectos, nos

33 Sobre el término apoikia, ver Canto, A. M., “Algo más sobre Marcelo, Corduba y las Colonias Romanas del año 45 a. C.", Gerion, 15, 1997, p. 263. Respecto a lulia loza, en un caso se utiliza la expresión epoikous (III, 1, 8), pero la ciudad es designada de forma directa como polis, por to que no es necesario este dato secundario.

${ }^{34}$ Tal vez hemos de ver a Asinio Polión como fuente, siguiendo a LASSERRE, F., Strabon ...., p. 8.

35 PÉDECH, P., op. cit., p. 239. 
ofrece, en pocas líneas, una catalogación de ciudades atendiendo a su status jurídico que, si bien no es tampoco muy completo ni claro en algunos casos, es más amplio que el de Estrabón. En nuestra opinión, en la obra de Plinio no hay un deseo tan palpable de ensalzar el nuevo régimen político ni de destacar sobre todo las posibilidades económicas de la zona, sino un espíritu más organizativo, administrativo y judicial, tal vez porque la Roma que Plinio contemplaba gozaba ya de un régimen imperial claramente implantado y porque la Bética que nos descubría Estrabón era ya comúnmente conocida en época pliniana.

Todas las ciudades citadas por Estrabón, tengan o no apelativo diferencial, se integran con bastante rigor en estos esquemas, valorándose de ellas los aspectos que más interesan a los eruditos griegos y romanos, no lo que quizás más útil podría ser a los propios hispanos. Así, los motivos por los que se citan las distintas ciudades se podrían encuadrar en el siguiente esquema (siempre modificable al gusto del consumidor, aunque no creo que las ideas básicas se vean alteradas):

- Observaciones y mediciones astronómicas o geográficas; ubicación de etnias: Gádira (III, 1, 5, Poseidonio, puestas de sol); Gádira-Calpe (III, 1, 8, distantes unos 800 estadios; carácter isleño de Gádira); Gádira (III, 1, 9, distancia hasta promontorio sagrado y bocas del Betis); Gádira-Calpe (III, 2, 1, franja en que se ubican los bastetanos); Munda (III, 2, 2, dista 1400 estadios de Carteya); Asta (III, 2, 2, a 100 estadios del puerto de Gádira); Hispalis (III, 2, 3, a unos 500 estadios de la desembocadura del Betis); Gádira (III, 2, 13, frente a Maurusia); Malaca (III, 4, 2, dista tanto de Calpe como ésta de Gádira); Malaca (III, 4, 6, cadena montañosa de la que se hace proceder al Sucro); Obulcon (III, 4, 9, dista de Corduba unos 300 estadios); Malaca (III, 4, 14, zona de bastetanos y oretanos); Gádira (III, 5, 3, isla, dista 750 estadios de Calpe); Gádira (III, 5, 8, mareas); Gádira-llipa (III, 5, 9, mareas hasta 700 estadios tierra adentro); Gádira como referente geográfico (II, 4, $1 ; I I, 4,8 ; I I, 5,14 ; \|, 5,15$; IV , 4, 6); galatai en Gádira (II, 4, 4); constelación de kabeiros vista desde Gádira (II, 5, 14); Gádira-Lixus (XVII, 3, 2, distan 800 estadios).

- Antigüedad y fundación colonial: ¿Calpe-Carteya? (III, 1, 7; antigua fundación); Iulia loza (III, 1, 8, fundación colonial romana integrada por gentes de Zelis, Tingi y colonos romanos); Corduba (III, 2, 1, fundación de Marcelo con indígenas selectos y romanos) ${ }^{36}$; Hispalis (III, 2 , 1 , colonia de romanos, pero oscurecida por el auge de Betis); Betis (III, 2, 1, hace sombra a Hispalis sólo por haberse asentado colonos

${ }^{36}$ Dejamos esta cuestión asi, porque no deseamos entrar ahora en la polémica de la fundación de Corduba, pero aprovecho el momento para recordar al lector los trabajos de A. M. Canto al respecto en los últimos tiempos: “Colonia Patricia Corduba: Nuevas hipótesis sobre su fundación y nombre"; Latomus, 50 , 1991, p. 846-857; y “Algo más ...", p. 153-281. 
de César, aunque no tenga gente ilustre: es una razón político-ideológica, no real); Tartesos (III, 2, 11; III, 2, 12; III, 2, 14); Malaca-Menace (III, 4, 2, fundaciones fenicia y griega respectivamente); Ábdera (III, 4, 3 , fundación fenicia).

- Estación naval, esteros, ríos o emporion comercial: ¿Calpe-Carteya? (III, 1, 7; antiguo puerto marítimo de los iberos); Belón (III, 1, 8: lugar de partida hacia Tingi, puerto comercial); Gádira (III, 1, 8, empresas navales); Asta y Nabrissa (III, 1, 9, en esteros); Ebura (III, 1, 9; no se especifica claramente que esté en estero, pero es la de la zona de Sanlúcar de Barrameda); Corduba-Gádira-Hispalis-Betis (III, 2, 1, situación ventajosa en ríos, esteros u orillas del mar); Gádira (III, 2, 1, empresas navales); Italica-llipa (III, 2, 2, sobre el Betis); Asta (III, 2, 2, en estero); Hispalis-llipa-Corduba-Castulo (III, 2, 3, navegabilidad del Betis); navegabilidad de los esteros (III, 2, 4-5); Asta-Nabrissa-OnobaOsonoba-Menoba (III, 2, 5, sobre los esteros; todo el tráfico se hace con Italia y Roma); las exportaciones turdetanas rivalizan con las libias, y van a Dicearquea=Puteoli y Ostia (III, 2, 6); Malaca (III, 4, 2, emporion para los africanos); Sexi (III, 4, 2, en la costa); comercio marítimo de Gádira (III, 4, 3, con África); Gádira (III, 5, 3, navegan en las más numerosas y mayores naves que van a Roma; viven en el mar; censan 500 caballeros).

- Riqueza económica: Menlaría (III, 1, 8, con industria de salazón); Belón (III, 1, 8: salazones); Corduba (III, 2, 1, riqueza de su campiña); Ilipa-Sisapon-Cotinas (III, 2, 3, abundancia de plata); Carteya (III, 2, 7, peces de gran tamaño); Malaca (III, 4, 2, salazón); Sexi (III, 4, 2, salazones); Gádira (III, 5,3, quinientos caballeros).

- Romanización: Gádira (III, 1, 8, amistad con romanos, parte del motivo de su prestigio, a pesar de estar en posición extrema); Gádira (III, 2,1 , estrechar lazos con los romanos mediante alianzas); ribereños del Betis (III, 2, 15, lengua, hábitos, condición jurídica de latinos y asentamiento de colonos romanos).

- Varia: Astigis-Carmon-Obulcon (III, 2, 2 más alejadas del Betis); MundaAtegua-Urson-Tuccis-Ulia-¿Aigoua-Aspavia? (III, 2,2, no lejos de Corduba, ciudades en que fueron vencidos los hijos de Pompeyo), Munda (III, 2,2 , metrópolis de su región); Carteya-Corduba (III, 2, 2, relacionado con hechos de la campaña de Munda); geografía mitica de Gádira (III, 2, 11); geografía mítica de Carteya (III, 2, 14; Carteya=Tartesos); geografía mítica de Odisea (III, 4, 3); Obulcon-Corduba-Gádira (III, 4, 9, en vía augusta); Munda (III, 4, 9, campaña bélica); Malaca (III, 4, 10, zona de bosque); geografía mítica de Gádira (III, 5, 4); Sexi-Onoba-Gádira (III, 5, 5, fundación de Gádira); Gádira (III, 5, 7, pozos); Gádira (III, 5, 8, mareas); Gádira (III, 5, 10, árbol curioso); Gádira y su vinculación marítima (I, 2, 31; II, $3,4 ; 1 I, 3,5 ; \mathrm{XVII}, 3,4)$; carácter isleño de Gádira (II, 5, 30). 
Ubicadas sobre el mapa, salvo las dudas que plantean los casos de Tartesos, Cotinas, Aigoua (si no es Aspavia) y Odisea (si no es Ulisi), el conjunto de ciudades béticas citadas cumple a rajatabla los parámetros generales que el propio Estrabón plantea para calibrar la importancia de una ciudad. De los cuatro casos citados, Tartesos entraría claramente en un pasado muy anterior al del propio Estrabón, aunque la referencia a la ciudad está muy en la línea de lo que él considera la geografía, que no es otra cosa que la evolución de una sociedad; por ello, el recuerdo de esta antigua civilización, muy vinculada por otra parte, a lo griego (y sospechosamente desligada de lo fenicio) ${ }^{37}$; es algo obligado para entender la evolución de este territorio, las diferencias entre Turdetania y las zonas próximas, la razón por la que aquí hay ciudades y gentes civilizadas y en otras zonas no, ... por otra parte, esta referencia contribuye a satisfacer las exigencias culturales de los eruditos a los que su obra iba dirigida, alimentando así el gusto de los griegos por las historias referentes al lejano occidente y sirviendo de excusa a su vez para la defensa que Estrabón hace de Homero, con justificaciones a veces tan desproporcionadas, que nos hacen perder el hilo de la auténtica narración ${ }^{38}$. De Cotinas nada podemos decir, salvo que se hallaria en una zona algo desvinculada del resto de las ciudades citadas, como es también el caso de Sisapon, junto a la que se la cita, como zonas de gran riqueza minera y ubicadas en relieves montuosos; en el mismo esquema, pero en zona diferente se hallaría Odisea (en el caso de que la identifiquemos con Ulisi=Loja, Granada). Las demás, se ligan casi sin excepción a un contexto viario y de comunicación:

- costeras o muy próximas a la costa: Osonoba, Onoba, Menoba, Ebura, Gádira, Belón, Menlaría, Calpe, lulia loza, Carteya, Malaca, Menace, Sexi, Ábdera.

- en la línea del Betis: Corduba, llipa, Italica, Hispalis, Betis, Nabrissa y Asta. Más alejadas del Betis, en expresión del propio Estrabón (III, 2, 2), Obulcon, Carmon y Astigis.

- vinculadas con la campaña de Munda: Ategua, Tuccis, Ulia, Munda, Urson y quizás Aigoua (si la identificamos con Aspavia).

Predomina, como hemos visto, un criterio de facilidad de comunicaciones y apertura al exterior, para propiciar las relaciones y el intercambio, para potenciar el comercio y fijar la riqueza y, por tanto, los impuestos que cada zona debe pagar. También el total de las ciudades, como aquéllas que reciben específicamente el apelativo de polis, se integran sin problemas dentro

37 Ciprés, P./Chuz Andreotti, G., op. cit., p. 125.

38 Gómez Espelosin, F. J., El descubrimiento ..., p. 237-239, p. 244-247; Prontera, F., «Notas sobre !beria en la Geografía de Estrabón", Estrabón e Iberia, p. 18-24; GARCIA BLANCO, J./GARCIA RAMON, J. L., op. cit., sobre la defensa de Homero en Estrabón, ver Geogr., I, 1, 2 (Homero es el primer poeta y el primer geógrafo griego), I, 1, 2-10 (descripción e interpretación del mundo conocido a través de Homero), I, 2, 1-40 (salpicado de referencias homéricas y de críticas de otros autores a la obra del poeta); Van Paassen, Ch, op. cit., p. 246. 
del esquema previo de importancia establecido por el propio Estrabón, y que ya hemos comentado. En ese caso, cabe preguntarse si estas ciudades son las más importantes, en general, o son únicamente las más importantes bajo la visión estraboniana de la historia y de la "utilidad» de esta ciencia y la geografía. Obviamente, parece que ambas cosas van unidas, y es lógico, ya que, cualquier historiador (o geógrafo, porque la definición de la geografía en Estrabón incluye muchos elementos que, para nosotros, serian historia) que escriba una obra que englobe, como la estraboniana, todo el orbe conocido, debe seleccionar y limitar la aparición de datos y esta selección en si misma, se hace atendiendo a criterios previos, criterios que, en este caso, están claramente fijados, pero que, en otros, con más problemas e indefinición, podrian también deducirse abstrayendo la metodologia seguida por el autor. Los lugares que Estrabón cita aparecen por poseer unos requisitos que con anterioridad el autor ha considerado básicos. De esos requisitos, habrá algunos que sean imprescindibles bajo cualquier criterio, pero otros lo son específicamente para el criterio greco-romano o, más concretamente, para el estraboniano, y es ahí donde ciudades tanto o más importantes que las citadas, no hallan su ubicación en este esquema; centros ibéricos de gran entidad no son recordados por Estrabón (aunque los mismos u otros tampoco lo son por Plinio o Ptolomeo, por citar dos autores básicos para la historia antigua de Hispania), pero eso no les priva de su importancia e influencia en el territorio, sólo les dificulta su conocimiento o su recuerdo a través de los tiempos. Esta relación de ciudades, como las que cita en otros lugares de su Geografía, es una selección hecha por él y al servicio de su propósito (no se le puede pedir que responda a otros esquemas), con un criterio selectivo subjetivo, pero que plantea ampliamente en su prefacio; él no pretende, como hemos dicho, escribir una geografía física, sino más bien social, de ahí que, por ejemplo, en Hispania parece destacar sus posibilidades económicas, pero en la descripción de Grecia se centra en lo cultural, tomando de cada zona lo que estima oportuno a su propósito ${ }^{39}$.

Por otra parte, las ciudades citadas, ¿son las que definen al conjunto de Turdetania, o son las que representan a algún sector concreto? Aquí nuestra respuesta creemos que es obvia, por los criterios que hemos apuntado a la hora de clasificarlas. La mayoría de las que reciben el apelativo de polis lo hacen al servicio de gustos o intereses greco-romanos, incluyendo lugares míticos, legendarios, fundaciones feno-púnicas y colonias o lugares que han recibido un aporte de colonos romanos. Las ciudades que podríamos incluir en una tradición indígena, no ligada directamente a lo fenicio-griego-romano, aparecen casi en exclusiva atendiendo a dos criterios:

- primero, su importancia económica y su ubicación en sectores donde la comunicación es fácil y fluida, estando ambos elementos directamente relacionados entre sí. No es éste lugar para entrar en la valora-

39 VAN PAASSEN, Ch., op. cit., p. 254-258. 
ción de los modelos, circuitos o criterios económicos que pueden convenir a una u otra cultura, pero lo que sí es evidente, creemos, es que los que aquí se recogen son los idóneos para la visión de Estrabón y para los intereses del estado romano. De hecho, la política romana de asentamientos en el llano, que Estrabón considera como el culmen de la vida civilizada, atendía a los intereses estratégicos, políticos y económicos de Roma, pero trajo consigo, no sólo el debilitamiento de los esquemas políticos indígenas, sino también la ruptura de sus circuitos económicos y de sus centros de influencia; la sistematización de una red viaria al servicio de los intereses y la mentalidad del vencedor, también provocó la ruina económica de los que quedaron fuera del sector beneficiado o los que, dentro de él, no supieron adaptarse a las nuevas formas de vida.

- segundo, incluídas bajo el criterio histórico-ideológico de su vinculación con la campaña de Munda: Urson, Munda, Ategua, Ulia, Tuccis. "Tras éstas encontramos Itálica e llipa a orillas del Betis, y más lejos Astigis, Carmon y Obulcon. Y también aquéllas en las que fueron vencidos los hijos de Pompeyo, Munda, Ategua, Urson, Tuccis, Ulia y Aspavia, todas ellas no lejos de Corduba». Adoptamos la traducción de Meana, razón por la que aparece citada Aspavia, de la que hemos dicho que no está plenamente probada su identificación con la Aigoua del texto de Estrabón. Pocas son las informaciones que recoge Estrabón de las ciudades aqui citadas, salvo para el caso de llipa, a pesar de la entidad que sabemos que tenian Italica, Astigis, Carmon y la propia Obulcon, tanto para los romanos (en los dos primeros casos), como para los indígenas (Obulcon y Carmon fueron dos importantes baluartes ibéricos, ejes articuladores de sus respectivos territorios durante la fase de conquista). Respecto a la geografía de la campaña de Munda conocemos por otras informaciones, entre las que hemos de considerar un caso privilegiado el relato del Bellum Hispaniense (pero la campaña fue tratada por muchos más autores $y$, además, es un hecho casi contemporáneo a Estrabón y de trascendental importancia para la historia de Roma, más, creemos, que para la propia historia de Hispania), muchos más datos sobre las ciudades que en ella intervinieron. Estos datos fueron aportados por una fuente directa, o sea, a través de la autopsia, por un individuo que conoció el escenario geográfico del enfrentamiento. Pero Estrabón desdeña a los autores latinos, y sólo en contadas ocasiones los utiliza como fuente para la redacción de su obra; si lo observamos, el autor no pretende ofrecer una obra actualizada sobre Hispania (para lo que necesitaría consultar buena parte de la información proporcionada por fuentes latinas, ya sean autores o archivos y documentación oficial), sino una buena síntesis obtenida de la consulta de los autores griegos que más confianza le merecen, eso sí, autores que, en la medida de lo posible, le 
garanticen dicha autopsia, aunque se remonten varios siglos respecto a su propia época. Las actualizaciones son, en este sentido, mínimas, $y$, generalmente, orientadas a la exaltación de la familia imperial y del proyecto político-ideológico de Augusto. Por lo tanto, también en estas citas hemos de ver más el planteamiento de base de Estrabón, que lo que sería la realidad objetiva del territorio.

Con todo, no pretendemos con estas reflexiones desprestigiar la figura ni la obra estraboniana, ni restar validez a las informaciones que nos proporciona, que han estado y siguen estando en la base de nuestro conocimiento y de nuestra visión de la historia antigua de la península ibérica. A fin de cuentas, salvo los que se entregan a una causa premeditada y premeditadamente, todos escribimos utilizando unos "criterios de objetividad" que creo que somos conscientes de que son los aplicables hoy día, pero que no son inmutables y que pueden no ser los mejor considerados en el futuro (la misma buena fe hemos de suponer a Estrabón) y, lo que es peor, todos escribimos bajo la influencia de nuestra propia formación educativa y cultural, de la que sólo conseguimos alejarnos un poco menos de lo que realmente pensamos (Estrabón, como todos, es un hijo de su época, de su formación y de sus intereses). Así, frente a los que sigan a Estrabón con una fe religiosa y a los que entren en una crítica excesiva y desproporcionada de su obra, pensamos que los datos proporcionados por el autor sobre Iberia son de un gran rigor y calidad, confrontados con las aportaciones de muchos de sus contemporáneos o de sus precedentes o continuadores; comete errores (como los cometemos todos) y, en su selección del material, omite datos que incluso para su época podríamos considerar básicos, pero, globalmente, nos ha transmitido la más completa descripción de lberia que tenemos hasta el momento (y también de la ecumene en su conjunto, lo que nos permite ejercicios comparativos dentro de un mismo criterio estructural, cosa que es muy importante) y que quizás tengamos para siempre. Sólo pretendemos destacar que, junto a la Iberia de Estrabón, complementaria (que no contradictoria) de ella, existe otra Iberia que, para bien o para mal, no se incluía dentro de los criterios básicos de un autor que, como decía Prontera, es el que plantea la más amplia introducción y justificación de su obra, dejando constancia clara de su metodologia y de sus prioridades, que puede que no sean las nuestras, pero que eso no las hace peores (ni mejores). 